\section{Should EJHP publish protocols?}

\author{
Phil Wiffen
}

An author recently wrote to European Journal of Hospital Pharmacy (EJHP) asking if we would consider publishing a protocol for a research project. This was something we had not considered and caused some debate among the editorial board. Among concerns was the viewpoint that protocols only signpost the research about to be undertaken and do not contain any results, so why publish them?

Over recent years, study protocols have become mainstream and some would consider an essential part of healthcare research. This has led to a number of important trial databases including ClinicalTrials.gov and a WHO database. ${ }^{1}$ Protocols lay out the researchers' plan in a publication that enables comparison with the later to be published results. This plan should give the objectives for the study, the methods to be employed and details of what outcomes will be measured and what analyses will be undertaken. The purpose of this is to provide transparency for the research and protect against biased practices such as data mining to find positive effects or hiding negative results. All that must be good.

In addition, the publication informs potential researchers that a study is about to undertake and this may inform future research or may prevent duplication of research on a similar topic. Protocols are fully citable and considered as original articles.

As with other study types, checklists for publishing protocols have been

Correspondence to Professor Phil Wiffen, Pain Research Unit, Churchill Hospital, Oxford OX3 7LE, UK; phil.wiffen@ndcn.ox.ac.uk published. The most widely used is called Standard Protocol Items: Recommendations for Interventional Trials (SPIRIT). ${ }^{2}$ The following is taken from the SPIRIT publication $^{3}$ :

The 33-item SPIRIT checklist applies to protocols for all clinical trials and focuses on content rather than format. The checklist recommends a full description of what is planned; it does not prescribe how to design or conduct a trial. By providing guidance for key content, the SPIRIT recommendations aim to facilitate the drafting of high-quality protocols. Adherence to SPIRIT would also enhance the transparency and completeness of trial protocols for the benefit of investigators, trial participants, patients, sponsors, funders, research ethics committees or institutional review boards, peer reviewers, journals, trial registries, policymakers, regulators, and other key stakeholders.

The checklist is worth a read as it covers all the key elements that are needed for publishing a protocol but is also of value to those wanting to write up a research project.

Such a move to publishing protocols is not new. As long ago as 1999, Ian Chalmers and Doug Altman suggested that medical journals should publish protocols to counteract poor research. ${ }^{4}$ The latest Declaration of Helsinki $(2013)^{5}$ also now includes the following statement: 'Every research study involving human subjects must be registered in a publicly accessible database before recruitment of the first subject.'

While this specifically mentions a database, publication is now also seen as important.
Finally, the publication of a protocol should ensure that the results of the research are published. Historically, many studies have not been published which is at best research waste given the resources needed to conduct research and at worse unethical as patients are exposed to studies which never add to knowledge or benefit the wider healthcare community.

After discussion we have decided that it is entirely appropriate for protocols to be published in EJHP. It is likely that these will be published online only but will be fully citable. We do not envisage that the numbers of such articles will be large. However, this will bring pharmacy research into line with the trend in wider healthcare research.

Competing interests None declared.

Provenance and peer review Commissioned; internally peer reviewed.

(c) European Association of Hospital Pharmacists 2019. No commercial re-use. See rights and permissions. Published by BMJ.

D Check for updates

To cite Wiffen P. Eur J Hosp Pharm 2019;26:1.

Published Online First 10 November 2018

Eur J Hosp Pharm 2019;26:1.

doi:10.1136/ejhpharm-2018-001774

\section{REFERENCES}

1 WHO. International Clinical Trials Registry Platform (ICTRP). http://www.who.int/ictrp/en/.

2 http://www.spirit-statement.org/

3 http://annals.org/aim/fullarticle/1556168/spirit-2013statement-defining-standard-protocol-items-clinicaltrials

4 Chalmers I, Altman DG. How can medical journals help prevent poor medical research? Some opportunities presented by electronic publishing. Lancet 1999;353:490-3.

5 https://www.wma.net/policies-post/wma-declarationof-helsinki-ethical-principles-for-medical-researchinvolving-human-subjects/ paragraph (35). 